\title{
Profissionals liberais e Pós-Graduação: PERCEPÇÕES E ESTRATÉGIAS EM RELAÇÃO À AVALIAÇÃO DA CAPES
}

\author{
Independent Professionals and Postgraduate Programs: perceptions \\ and strategies in relation to the CAPES evaluation
}

\section{Profesionales Liberales y Pos Grado: percepciones y estrategias en relación a la evaluación de la CAPES}

RESUMo O objetivo do estudo foi compreender as percepções dos profissionais liberais, das áreas de ciência social aplicada, engenharias e saúde, vinculados a programas de pós-graduação, sobre a avaliação da CAPES. A pesquisa abrangeu 18 profissionais liberais que atuam, também, como professores em 11 programas de cinco universidades comunitárias catarinenses. Foi utilizada a entrevista com roteiro semiestruturado e na análise foram considerados os princípios da hermenêutica e da dialética, em diálogo com a ótica sociológica de Pierre Bourdieu. As respostas dos participantes demonstraram que há três problemas a serem superados no modelo de avaliação da CAPES: as regras do processo de avaliação se modificam durante o jogo, ou seja, as novas regras são apresentadas quando o quadriênio está concluído e não antes de iniciá-lo; valorizam-se mais a quantidade de produtos do que a sua qualidade; pouca importância é atribuída à relevância da pesquisa. Os entrevistados explicitaram estratégias adotadas para manter a pontuação exigida na avaliação da CAPES, destacando-se: trabalhar nos finais de semana, à noite e na madrugada; trabalhar em colaboração com orientandos e professores; aproveitar ao máximo os dados, diagnósticos e os contatos do campo profissional, entre outras.

PalaVras-chave: Profissional liberal. Pós-Graduação. Avaliação.

ABStRACT The objective of the study was to understand the perceptions of independent professionals, in the areas of applied social science, engineering and health, linked to postgraduate programs, on the CAPES evaluation. The research included 18 independent professionals who also act as teachers in 11 programs of five community universities in Santa Catarina. The interview with semi-structured script was used and in the analysis the principles of hermeneutics and dialectics were considered in dialogue with the sociological perspective of Pierre Bourdieu. Participant's responses demonstrated that there are three problems to be overcome in the CAPES evaluation model. The problems were: the rules of the evaluation process change during the game, that is, the new

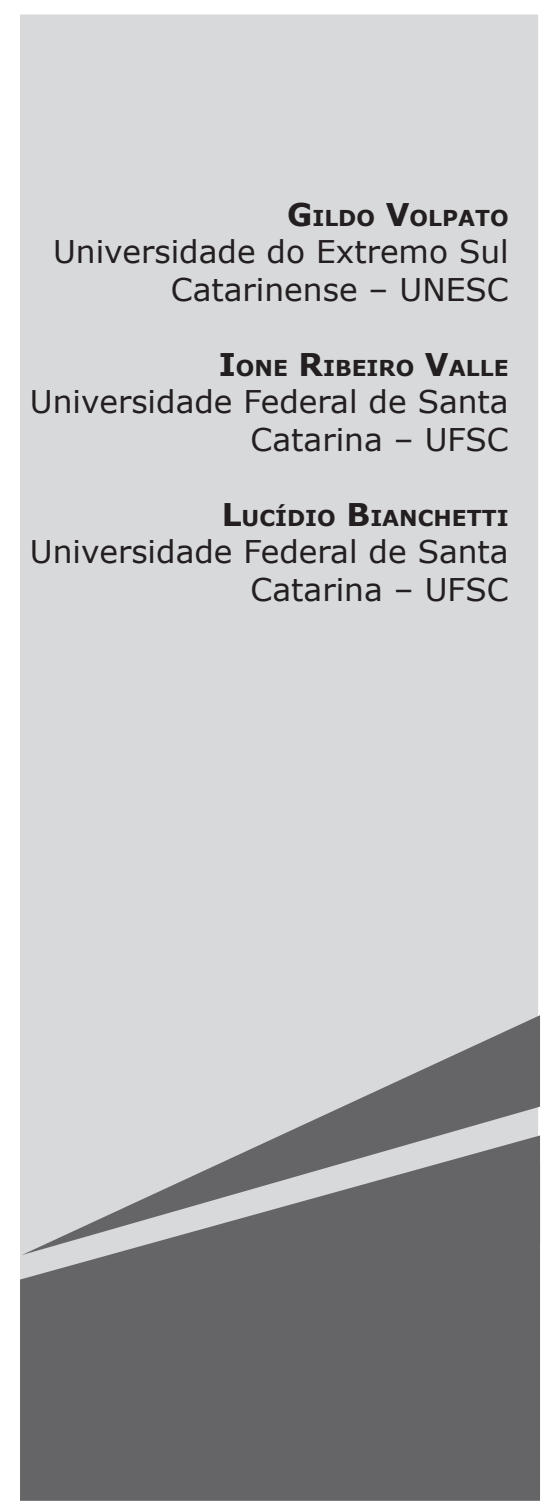


rules are presented when the four-year period is completed and not before it starts it; the quantity of products is valued more than their quality; little importance is attached to the relevance of the research. The interviewees explained strategies adopted to maintain the required score in the CAPES evaluation, especially: working on weekends, at night and at dawn; work in collaboration with students and teachers; make the most out of the data, diagnoses and contacts of the professional field, among others.

KEY-WORDS: INDEPENDENT PROFESSIONAL. POSTGRADUATE PROGRAMS. EVALUATION.

RESUMEN El objetivo del estudio fue comprender las percepciones de los profesionales liberales, de las áreas de ciencia social aplicada, ingenierías y salud, vinculados a programas de pos grado, sobre la evaluación de la CAPES. La investigación abarcó 18 profesionales liberales que actúan, también, como profesores en 11 programas de cinco universidades comunitarias catarinenses. Fue utilizada la entrevista con plan de trabajo semiestructurado y en el análisis fueron considerados los principios de la hermenéutica y de la dialéctica, en diálogo con la óptica sociológica de Pierre Bourdieu. Las respuestas de los participantes demostraron que hay tres problemas a ser superados en el modelo de evaluación de la CAPES: las reglas del proceso de evaluación se modifican durante el juego, o sea, las nuevas reglas son presentadas cuando el cuadrienio está concluido y no antes de iniciarlo; se valorizan más la cantidad de productos de que su calidad; poca importancia es atribuida a la relevancia de la investigación. Los entrevistados explicitaron estrategias adoptadas para mantener la puntuación exigida en la evaluación de la CAPES, destacándose: trabajar los finales de semana, de noche y en la madrugada; trabajar en colaboración con orientados y profesores; aprovechar al máximo los datos, diagnósticos y los contactos del campo profesional, entre otras cosas.

Palabras clave: Profesional liberal. Pos Grado. Evaluación.

\section{INTRODUÇÃo}

D e modo diferente de outras categorias de trabalhadores, os profissionais liberais são autônomos em seu processo de trabalho. Seus órgãos de classe criam suas próprias regras, delimitando o campo de atuação e as normas de funcionamento, em defesa de seus próprios interesses. No entanto, alguns profissionais liberais, além de atuarem no mercado de trabalho, buscaram a carreira acadêmica, atuando concomitantemente como professores universitários, sendo submetidos constantemente a processos avaliativos.
Em meados da década de 1990, Cunha e Leite (1996) identificaram a falta de motivação dos profissionais liberais, professores universitários, em fazer mestrado e doutorado, pelo fato de ser mais valorizado o reconhecimento especializado que exerciam no consultório, no escritório e em outros espaços de atuação profissional do que a titulação acadêmica e as possibilidades e ganhos diretos e/ou indiretos dela advinda.

Uma das questões que ficaram evidenciadas nos estudos de Volpato (2010) foi o quanto a Lei $n^{\circ}$. 9.394/1996, que estabelece as diretrizes e bases da educação nacional 
(LDBEN), e as políticas de avaliação adotadas pelo Estado impactaram na universidade e na vida de seus professores. Apesar de ainda haver o reconhecimento especializado no âmbito da profissão liberal, tudo indica que os profissionais liberais professores passaram a dar maior valor à titulação, à pesquisa, à pós-graduação (PG) e à publicação científica no âmbito universitário.

As pesquisas de Bazzo (2007) e Volpato (2010) indicaram um movimento dos professores universitários, que também são profissionais liberais, em busca da titulação e do ingresso em programas de pós-graduação (PPGs), dado o imperativo das exigências da LDBEN e das avaliações externas, mas também porque a pesquisa e a veiculação do conhecimento contribuem para o prestígio na universidade, com possíveis repercussões para o campo profissional.

Da mesma forma que a avaliação é recorrente na graduação, aqueles que ingressaram na $\mathrm{PG}$, certamente adentraram em outro campo minado por avaliações, em especial aquelas postas em prática pela Coordenação de Aperfeiçoamento de Pessoal de Nível Superior (CAPES), dadas as exigências de produção, principalmente de produtos considerados como qualificados.

Estudar a percepção dos profissionais liberais pesquisadores, vinculados aos PPGs, submetidos à avaliação da CAPES, significa levantar interrogações sobre seus efeitos no processo de produção e veiculação do conhecimento e acerca das estratégias por eles adotadas, tendo em vista a dupla jornada de trabalho. Como afirma Bourdieu (1998, p. 37), todo problema de pesquisa "foi socialmente produzido, num trabalho colectivo de construção da realidade social".

A partir desse cenário é que se definiu como objetivo deste artigo a compreensão das percepções dos profissionais liberais professores/pesquisadores, vinculados aos PPGs, sobre as repercussões da avaliação da CAPES na vida acadêmica e no campo profissional, bem como, suas estratégias de atuação para responder às exigências de produção/publicação dessa avaliação.

A abordagem da pesquisa foi qualitativa e na análise de dados foram considerados os princípios da hermenêutica e da dialética, em diálogo, principalmente, com a ótica sociológica de Pierre Bourdieu. A pesquisa foi realizada no âmbito de cinco universidades comunitárias, localizadas no litoral catarinense, do extremo sul ao norte do Estado. A partir do contato com as universidades, chegou-se a 18 professores pesquisadores vinculados a 11 PPGs, que continuam, também, a atuar como profissionais liberais, dispostos a colaborar com a pesquisa. A partir daí deu-se a coleta de dados por meio de entrevistas com roteiro semiestruturado.

Para garantir o anonimato, os entrevistados foram nomeados pela letra $\mathrm{E}$ acompanhada por números, por exemplo, E01, E02, E03..., respeitando a ordem alfabética de seus nomes. No quadro a seguir podem ser observados dados gerais de cada um dos entrevistados, como o curso de formação inicial em nível de graduação, o curso de doutorado frequentado, o PPG no qual se inserem e o tempo de atuação na PG. 
Quadro 1. Dados dos entrevistados.

\begin{tabular}{|c|c|c|c|c|}
\hline N. & Graduado(a) em & Doutor(a) em & PPG em que atua & $\begin{array}{c}\text { Tempo de } \\
\text { atuação na PG }\end{array}$ \\
\hline E01 & Administração & $\begin{array}{l}\text { Engenharia de } \\
\text { Produção }\end{array}$ & $\begin{array}{l}\text { Mestrado em } \\
\text { Administração }\end{array}$ & 10 anos \\
\hline E02 & Farmácia & $\begin{array}{l}\text { Farmácia (Análises } \\
\text { Clínicas) }\end{array}$ & Mestrado em Química & 15 anos \\
\hline $\mathrm{E} 03$ & $\begin{array}{l}\text { Engenharia Civil e } \\
\text { Administração }\end{array}$ & $\begin{array}{l}\text { Engenharia de } \\
\text { Produção }\end{array}$ & $\begin{array}{l}\text { Mestrado em } \\
\text { Administração }\end{array}$ & 7 anos \\
\hline E04 & Fisioterapia & Neurociências & $\begin{array}{l}\text { Mestrado e Doutorado } \\
\text { em Ciências da Saúde }\end{array}$ & 4 anos \\
\hline E05 & Administração & $\begin{array}{l}\text { Engenharia } \\
\text { e Gestão do } \\
\text { Conhecimento }\end{array}$ & $\begin{array}{l}\text { Mestrado em } \\
\text { Administração }\end{array}$ & 8 anos \\
\hline Eo6 & Direito & Ciência Jurídica & $\begin{array}{l}\text { Mestrado e Doutorado } \\
\text { em Direito }\end{array}$ & 1 ano \\
\hline E07 & $\begin{array}{c}\text { Administração de } \\
\text { Empresas }\end{array}$ & Administração & $\begin{array}{l}\text { Mestrado em Gestão de } \\
\text { Políticas Públicas }\end{array}$ & 7 anos \\
\hline Eo8 & Medicina & Ciências & $\begin{array}{l}\text { Metrado e Doutorado em } \\
\text { Saúde e Meio Ambiente }\end{array}$ & 4 anos \\
\hline Eo9 & $\begin{array}{l}\text { Ciências } \\
\text { Contábeis }\end{array}$ & Administração & $\begin{array}{l}\text { Mestrado em } \\
\text { Administração }\end{array}$ & 5 anos \\
\hline E10 & Odontologia & Odontologia & $\begin{array}{l}\text { Mestrado e Doutorado } \\
\text { em Ciências da Saúde }\end{array}$ & 11 anos \\
\hline E11 & $\begin{array}{c}\text { Engenharia } \\
\text { Florestal }\end{array}$ & $\begin{array}{l}\text { Engenharia } \\
\text { Florestal }\end{array}$ & $\begin{array}{c}\text { Mestrado em Engenharia } \\
\text { Florestal }\end{array}$ & 7 anos \\
\hline E12 & $\begin{array}{l}\text { Engenharia } \\
\text { Química }\end{array}$ & $\begin{array}{l}\text { Engenharia de } \\
\text { Produção }\end{array}$ & $\begin{array}{l}\text { Mestrado em Gestão, } \\
\text { Internacionalização e } \\
\text { Logística }\end{array}$ & 2 anos \\
\hline E13 & Direito & $\begin{array}{l}\text { Direito Ambiental e } \\
\text { Sustentabilidade }\end{array}$ & $\begin{array}{l}\text { Mestrado e Doutorado } \\
\text { em Direito }\end{array}$ & 5 anos \\
\hline E14 & Medicina & Epidemiologia & $\begin{array}{l}\text { Mestrado e Doutorado } \\
\text { em Ciências da Saúde }\end{array}$ & 10 anos \\
\hline E15 & Medicina & Ciências & $\begin{array}{l}\text { Mestrado e Doutorado } \\
\text { em Saúde e Meio } \\
\text { Ambiente }\end{array}$ & 4 anos \\
\hline E16 & Medicina & $\begin{array}{l}\text { Saúde da Criança e } \\
\text { do Adolescente }\end{array}$ & $\begin{array}{c}\text { Mestrado e Doutorado } \\
\text { em Saúde e Meio } \\
\text { Ambiente }\end{array}$ & 15 anos \\
\hline E17 & $\begin{array}{c}\text { Administração, } \\
\text { Contabilidade, } \\
\text { Direito e } \\
\text { Economia }\end{array}$ & $\begin{array}{c}\text { Administração e } \\
\text { Turismo }\end{array}$ & $\begin{array}{l}\text { Mestrado em } \\
\text { Desenvolvimento } \\
\text { Socioeconômico }\end{array}$ & 5 anos \\
\hline E18 & $\begin{array}{c}\text { Direito e } \\
\text { Administracão }\end{array}$ & Direito & Mestrado em Direito & 1 ano \\
\hline
\end{tabular}

Fonte: Elaborado pelos autores, a partir de dados da pesquisa. 
Percebe-se que os entrevistados são oriundos de diferentes áreas de conhecimento como saúde, ciências sociais aplicadas e engenharias. Nota-se que três deles possuem mais de uma graduação nessas mesmas áreas. O tempo de atuação na PG varia entre $1 \mathrm{e}$ 15 anos. Dos 18 participantes da pesquisa, 13 são homens e cinco são mulheres, evidenciando que ainda há o predomínio de homens nesses campos de atuação.

A seguir, delinearemos as principais referências teóricas que embasam o presente estudo e a apresentação dos resultados das análises e interpretações dos dados coletados.

\section{OS PRESSUPOSTOS DA AVALIAÇÃO DA CAPES E AS PERCEPÇÕES DOS PESQUISADOS}

Nos últimos anos, de agência avaliadora da PG brasileira, a própria CAPES, além de avaliar, passou a ser avaliada e tomada como objeto de estudo, dado o grau de sua importância no cenário universitário e os impactos causados nas Instituições de Ensino Superior (IES), sobretudo no âmbito da PG e dos seus agentes, ou seja, os professores pesquisadores, bem como, seus discentes.

A Campanha Nacional de Aperfeiçoamento de Pessoal de Nível Superior (como foi chamada inicialmente a (APES) foi criada em 11 de julho de 1951, pelo Decreto $n^{\circ}$. 29.741, com o objetivo de "assegurar a existência de pessoal especializado em quantidade e qualidade suficientes para atender às necessidades dos empreendimentos públicos e privados que visam ao desenvolvimento do país" (BRASIL, 2018). Assim, a CAPES foi criada no início do segundo governo de Getúlio Vargas (1950-1954), quando todas as ações do Estado brasileiro se voltavam ao projeto de construção de uma nação desenvolvida e independente, num contexto de industrialização pesada e de aumento da complexidade da administração pública, o que exigia a formação de especialistas e pesquisadores nos mais diversos ramos de atividade.

O principal e primeiro desafio da "Campanha”, sob a liderança de Anísio Teixeira
(1900-1991), foi criar a PPG e fazer dela o meio, por excelência, de transformação e de modernização da universidade brasileira (MENDONÇA, 2003). O objetivo era formar professores para o ensino superior, uma vez que eram precárias as condições do quadro docente da época, bem como, dos meios para o desenvolvimento da pesquisa. A partir de 1964, a CAPES passa a chamar-se Coordenação de Aperfeiçoamento de Pessoal de Nível Superior, e seu principal objetivo, até 1990, continuava sendo o da formação de quadros para atuar no magistério superior.

Com o Decreto $n^{\circ}$. 86.791/1981, que extingue o Conselho Nacional de Pós-Graduação, o papel da CAPES é fortalecido, pois ela passa a ser a responsável pela elaboração do Plano Nacional de Pós-Graduação (PNPG), e recebe a incumbência de coordenar a avaliação da PG.

No início de 1990, no governo Collor de Mello (1990-1992), pela Medida Provisória nº. 150, de 15 de março de 1990, a CAPES foi extinta, e após mobilização de pesquisadores, coordenadores de PPGs, pró-reitores de pesquisa e de PG, os quais contaram com o apoio do próprio Ministério da Educação (MEC), a situação foi revertida e nesse mesmo ano ela voltou a ser criada. Em 1992, foi instituída como Fundação Pública e nesse movimento de recriação e de transformação da condição jurídica, seu paradigma predominante de formação de docentes é modificado, passando a visar à formação de pesquisadores (KUENZER; MORAES, 2005; SAVIANI, 2006). Para alcançar esse intento, a CAPES passa a exercer com força e poder a sua condição de coordenadora da avaliação, instituída pelo Decreto $\mathrm{n}^{\circ}$. 86.791/1981.

Para levar a efeito a avaliação, a CAPES buscou parcerias com professores e pesquisadores das diversas áreas, por meio de associações científicas, das quais algumas ela mesma incentivou a criação. Por meio desse processo, se constituíram as Comissões de Avaliação das áreas e o Comitê Técnico Científico (CTC), o último como instância que ratifica ou retifica os resultados dos trabalhos da Comissão 
de Avaliação das áreas. Essa estratégia acabou por materializar-se, ao longo dos anos, em um tipo de avaliação padronizada, que supostamente poderia ser aplicada por e para todos, independentemente das especificidades das áreas (BIANCHETI, 2009).

A partir de então, foi implantada uma política de resultados para a PG do país, claramente observável ao longo das duas últimas décadas. Essa política intensifica-se na medida em que a CAPES assume, concomitantemente, a responsabilidade pela avaliação e pelo fomento da PG, propiciando questionar a possibilidade de uma avaliação formativa, quando estritamente vinculada ao fomento.

Nesse sentido, Bianchetti (2009, p. 70) alerta que essa forma de avaliar e de financiar a PG não figura como indicação opcional, pois "estamos diante de uma indução, com pouca ou praticamente nenhuma possibilidade de formas ou modelos alternativos", uma vez que a CAPES "tem na díade avaliação-financiamento argumentos poderosos para serem confrontados, e muito persuasivos para não serem seguidos" (p. 78).

A forma como se originou e se estruturou, o “campo CAPES", expressão utilizada por Bianchetti (2009), a partir do conceito de campo de Bourdieu (2004, p. 20), que nada mais é do que "esse espaço relativamente autônomo, esse microcosmo dotado de suas leis próprias" que no plano simbólico, "se situa ao nível do ritual, não colocando em causa os princípios de poder que estruturam o campo" (BOURDIEU apud ORTIZ, 1983, p. 23).

Para Bourdieu (2017, p. 70), “o campo universitário reproduz na sua estrutura o campo do poder cuja ação própria de seleção e de inculcação contribui para reproduzir a estrutura". Por isso, segundo ele, o campo científico "é um campo de forças dotado de uma estrutura, e também um campo de lutas para conservar ou transformar esse campo de forças" (BOURDIEU, 2001, p. 69).

Tudo indica que a CAPES, enquanto campo, congrega todos os outros subcampos, ou seja, o das diferentes áreas de conhecimento e faz que seus agentes, nesse caso os pesqui- sadores das diferentes áreas, acabem desenvolvendo habitus comuns, que para Bourdieu (apud ORTIZ, 1983, p. 15) se refere a um "sistema de disposições duráveis, estruturas estruturadas predispostas a funcionarem como estruturas estruturantes". Para ele "o habitus se sustenta, [...] através de 'esquemas generativos' que por um lado, antecedem e orientam a ação e, por outro, estão na origem de outros 'esquemas generativos' que presidem a apreensão do mundo enquanto conhecimento" (BOURDIEU apud ORTIZ, 1983, p. 16).

No entanto, como afirmam Bianchetti, Valle e Pereira (2015, p. 48):

[...] se o campo científico submete-se à tirania de uma norma ou de uma ordem, subordina, de forma deliberada ou sob a força de mecanismos coercitivos, suas finalidades acadêmicas a finalidades práticas, seus critérios científicos a critérios normativos, correndo o risco de limitar a produção científica a 'competências estratégicas, a demandas ad hoc.

Horta (2009) apresenta importante contribuição a partir de análises das críticas e sugestões encaminhadas à CAPES pelos coordenadores de PPGs, por meio do Coleta CAPES de 2004 , as quais classificou em cinco blocos.

O primeiro, sendo o que congrega o maior número de posicionamentos, agrupa as críticas ao caráter homogeneizador do modelo de avaliação da CAPES. Um grande número de coordenadores, de diferentes áreas de conhecimento, foca a necessidade de se levar em conta, na avaliação, a especificidade de cada grande área, de cada área, de cada PPG e as diferentes regiões do país. A presente pesquisa ratifica essa posição por parte de alguns entrevistados, mesmo na condição de pesquisadores dos PPGs, como pode ser percebido no depoimento a seguir:

Em Medicina I, no nosso PPG, eles fazem muita pesquisa pré-clínica, 
em animais A minha área é epidemiologia, Então, realmente a gente tem mais dificuldade para publicações por tratar-se de estudos populacionais. - Então, eu sempre reivindicava: por favor, o meu recredenciamento poderia ter pontuação menor que os outros pesquisadores, ou o Qualis deveria ser considerado na minha área, que daí os journals pontuam mais (E14).

O segundo bloco engloba as críticas ao modelo de avaliação no que se refere à ênfase dada aos indicadores quantitativos e à produção bibliográfica. Nesse bloco, os coordenadores deram a sugestão de que se leve em conta no processo avaliativo os aspectos qualitativos e as atividades de formação. Nesse mesmo sentido, nossos entrevistados assim se manifestaram: A gente fica se preocupando mais em ter a pontuação e atender à CAPES, porque tem que gerar publicação, pontuação, do que ficar se dedicando a aprofundar mais alguns estudos, que são mais relevante (E03). Algumas vezes a gente questiona se é importante essa produção, o número, ou não seria mais importante uma qualidade? (E06).

O terceiro bloco se refere às críticas sobre a ausência da valorização da dimensão social dos PPGs. Nesse bloco, os coordenadores propõem a inclusão dessa dimensão no modelo de avaliação da CAPES. Uma das nossas entrevistadas posicionou-se nesse mesmo sentido: Agora a gente está tentando atender também a parte social, na avaliação, que é necessário nos adaptar. Toda essa ginástica que a gente faz para atender a CAPES (E09), o que pode ser interpretado como um quesito que vem sendo contemplado nas últimas avaliações da CAPES.

O quarto bloco abarca a questão da inserção internacional. Enquanto alguns coordenadores de PPGs bem avaliados defendem a valorização dessa dimensão, especialmente quanto à difusão da produção bibliográfica, outros a criticam, por desconsiderar a especificidade das áreas. Dois dos nossos interlocu- tores da área da medicina falaram sobre as dificuldades da inserção internacional. O primeiro assim se pronunciou: Para teres uma noção, na área de medicina II, nós não temos nenhum periódico brasileiro $\mathrm{B} 1$, isso dificulta um monte (E10). O segundo entrevistado enfatizou:

Uma coisa que me deixa chateado é
o preconceito que existe com o pes-
quisador latino-americano. [...] Tem
paper que a pessoa sofre, ele roda
hemisférios, cinco, seis revistas
para você publicar. E ultimamente,
está cada vez mais difícil você publi-
car em revista internacional de qua-
lidade (E15).

O quinto e último bloco trata das consequências do modelo de avaliação para as diferentes áreas e PPGs. Os coordenadores ressaltam o quanto a avaliação interfere no cotidiano dos PPGs, seja no sentido de definir mudanças para atender às exigências da CAPES, seja recorrendo às Comissões de Avaliação para buscar respaldo voltado à solução de problemas internos, seja ainda no sentido de abdicar da autonomia. Alguns consideram a avaliação como instrumento que estimula a competição entre as áreas e as grandes áreas.

Quanto às mudanças de procedimento da CAPES, um dos pesquisadores assim se manifestou: às vezes a CAPES é um pouco maleável demais, imprevisível, do ponto de vista de que é de um jeito, e daqui uns seis meses já corre um boato que é de outro. Então, a gente fica muito inseguro em relação a isso (E05).

Ao mesmo tempo em que apresentam críticas e sugestões para o aperfeiçoamento do processo de avaliação, eles também tecem elogios à CAPES e ao processo de avaliação em vigência. Embora se façam críticas à forma como vem sendo desenvolvida, principalmente em relação às questões já colocadas, ao que tudo indica, ninguém quer abrir mão da avaliação, ou suprimi-la. Até porque diante do cenário atual, do mundo globalizado e dos processos de internacionalização a que estamos submetidos e/ou nos submetemos, é impossí- 
vel defender uma postura laissez faire, como bem disseram Bianchetti, Valle e Pereira (2015). Alguns dos nossos entrevistados também se expressaram nessa mesma perspectiva: Eu acredito que seja importante, como qualquer coisa, ter avaliação. Eu só tenho minhas dúvidas em relação aos critérios e a pressão que a gente tem em publicar (E03). Eu acho que é um caminho, podiam ser seguidos outros, mas esse foi um bom caminho. De certa forma, nós melhoramos, tinha muito problema. Então eu acho que de alguma forma tem que ter avaliação. Acho que é uma forma eficaz (Eog).

A universidade brasileira, segundo Sguissardi (2009, p. 171-172), dada a sua tradição de falta de autonomia e de cultura de avaliação e autoavaliação:

[...] e porque sempre se ateve a responder a demandas externas, estatais, de avaliação, a relação da comunidade científica da pós-graduação com o "Modelo CAPES de Avaliação" é de profunda ambiguidade. Ao mesmo tempo em que reconhece como legítimo, o teme. Ao mesmo tempo em que o teme, e talvez por não identificar adequadamente sua natureza e especificidade de regulação e controle em nome do Estado, Ihe atribui o poder de definir a efetiva qualidade que devem ter os Programas de Pós-Graduação. E a qualidade da pós-graduação brasileira passa a ser a que for definida pelo "Modelo CAPES de Avaliação".

Conforme um dos nossos entrevistados: Tudo bem, vamos brigar para mudar as regras? Vamos brigar para mudar as regras, mas enquanto elas não mudam, vamos nos adaptar, vamos fazer (E07).

De certa forma, trata-se de uma luta simbólica, como afirma Valle (2007), na medida em que visa à produção de sentidos comuns e revela a posição específica do Estado, que dispõe do monopólio da dominação legítima e, nessa condição, procura inculcar uma definição também legítima do mundo social.

Em outras palavras, é importante reconhecer que a indução por parte do Estado no sentido de primar pela pesquisa e pela cientificidade dos PPGs foi positiva. Contudo, como afirmam Kuenzer e Moraes (2009, p. 186 -187):

[...] são manifestos alguns aspectos negativos e não resolvidos no novo modelo, que podem ser resumidos em dois pontos principais. Por um lado, a exacerbação quantitativista que, como de resto ocorre com os modelos econométricos, só avalia o que pode ser mensurado [...]. Por outro lado, as exigências relativas à produção acadêmica geraram um verdadeiro surto produtivista em que conta é publicar, não importa qual versão requentada de um produto, ou várias versões maquiadas de um mesmo produto.

Em consonância com essa reflexão, assim se expressa uma entrevistada:

Num grupo de estudos ou num projeto de pesquisa, quando começa a cobrar, "Ah, tu tens que entregar, tu tens que produzir dois, três, quatro artigos, vira um número e não mais um produto importante". Poderia sair, de repente, um único artigo, mas bem estruturado, com bastante substância de pesquisa, fundamentado. Aí a gente pega um tema, pulveriza e acaba saindo vários artigos enquanto poderia sair um trabalho muito bem feito (E06).

Nossos entrevistados fazem críticas consistentes e apontam questões que merecem a nossa atenção, tendo em vista as possibilidades de contribuição para a melhoria desse processo de avaliação. As críticas e questões podem ser resumidas em três dimensões, a saber: 
a) A CAPES muda a regra do jogo olhando para o retrovisor: os entrevistados de forma recorrente afirmaram que não é justo a CAPES fazer as avaliações e requalificações das revistas e periódicos após o término do quadriênio e aplicá-las para a pontuação do mesmo período. Isto é que as avaliações deveriam ser feitas para divulgar aos pesquisadores a classificação para o quadriênio que se inicia e não para julgar o passado das publicações. Esse é um ponto importante a ser revisto, pois como afirmou um dos entrevistados:

Você não sabe qual Qualis vai valer, porque vai mudar, a gente está sempre correndo atrás. Isso para nós é uma tragédia. Se tiver que modificar, é para beneficiar, não para prejudicar. Então, essa é uma lógica da CAPES inconcebível para qualquer pesquisador, pois vai contra o processo natural de um ser humano, porque ele almeja ir galgando, não almeja dando um passinho para trás (E01).

Mesmo mostrando-se insatisfeitos os pesquisadores trabalham nessa lógica implementada pela CAPES. Como afirma Bourdieu (1997, p. 3): "Obedecemos bem além dos limites nos quais se exerce a coerção do Estado. Obedecemos sem sofrer coação direta e mesmo nas condições em que toda coerção potencial, ou virtual está ausente".'

b) A CAPES induz a quantidade/o número de publicações: como demonstrado em outros estudos, os profissionais liberais pesquisadores falaram sobre o sistema de avaliação da CAPES no sentido quantitativo, em que o número de publicações acaba tendo um valor em si. Quando as estatísticas e os elementos quantitativos são confrontados com a qualidade, não há ufanismo que resista, e dão lugar a questionamentos. A ênfase na dimen-

Tradução para o português feita por lone Ribeiro Valle. Transcrição e edição do documento audiovisual registrado em francês pelo Service Audiovisuel de l'Université de Rouen, com o título "La Domination", realizadas por Charles Soulié. Conferência, ou "Lição descentralizada", proferida por Pierre Bourdieu na Universidade de Rouen, no dia 26 de novembro de 1997. são quantitativa da avaliação aparece em muitas entrevistas e pode ser representada pelo depoimento a seguir:

Tu tens que estar sempre publicando, então às vezes você não está pesquisando ou publicando exatamente naquilo que tu queres. Às vezes tu tens que pesquisar ou publicar algumas coisas para ter pontuação. Essa pressão é que eu acho que é o lado ruim da história. A gente fica se preocupando mais em gerar publicação para alcançar a pontuação e atender a CAPES, do que ficar se dedicando mais, aprofundando mais alguns estudos, que são mais relevantes (E03).

c) A CAPES pouco ou nada considera quanto à relevância da pesquisa: a produção exigida pela CAPES, segundo os entrevistados, tende a desconsiderar aspectos qualitativos das pesquisas e dos conhecimentos produzidos, o que pode induzi-los a fazer escolhas que levam à produção de artigos em detrimento da relevância social de seus achados. O depoimento a seguir pode caracterizar essa dimensão:

Tive um doutorando que disse: "A CAPES está - nas palavras dele ferrando com a ciência brasileira, porque quer número de artigo, quer isso, quer aquilo". E de certa forma ele tem razão, a crítica é pertinente. A forma como foi trabalhada nos últimos anos, muito focada em números, muito focada na produção de artigos, na quantidade, sem necessariamente ver o impacto dessas pesquisas, a função social dessas pesquisas (E10).

Um dos entrevistados relaciona a relevância da pesquisa e da publicação à geração de patentes:

Eu acho que deve ter uma avaliação um pouco mais qualitativa. Qual o impacto realmente dessa ciência? Eu 
acho que aí vem a patente. Talvez assim valesse a pena ter o trabalho de sentar para escrever uma patente. Porque a gente sabe que podemos escrever vários artigos e ter um currículo bom para a CAPES. Mas eu não quero sentar para escrever qualquer coisa. Então, realmente você vai escrever patente de algo que é relevante, que vai impactar (E04).

Importante considerar que esse aspecto também está contemplado na avaliação da CAPES, e os impactos devem ser sociais no sentido lato, pois é de se imaginar que há conhecimento de que a "transformação de invenções científicas em inovações geradoras de novos produtos [é também geradora] de novos lucros no mundo econômico" (BOURDIEU, 2004, p. 54).

Quatro entrevistados, apesar de empreenderem esforços pessoais e coletivos para cumprir as demandas da CAPES, demonstraram resistir à pesquisa utilitária, quantitativa ou à corrida competitiva entre os pares, visando apenas à produção de artigos. Vejamos dois depoimentos:

Acho que se eu quisesse me dedicar mais à clínica [como profissional liberal], eu ainda conseguiria aqui [na universidade] manter a publicação exigida pela CAPES, só que como eu falei, é a minha escolha, eu sou mais de fazer a pesquisa, de estar descobrindo algo novo, do que estar realmente atendendo à CAPES (E04).

Vamos brigar para mudar as regras, mas enquanto elas não mudam, vamos nos adaptar, vamos fazer. É demais? É demais! Agora eu também não vou muito além do limite para essas coisas da CAPES. Quero ser [bolsista] produtividade CNPq? Não, eu não quero ser produtividade CNPq, pode ser você, você, não tem problema. Quero fazer, quero cumprir o mínimo exigido da CA$P E S$, mas o que quero é deixar um legado de algumas coisas desenvolvidas na minha área que depois vão se tornar referência (E07).

Um dos entrevistados aponta o conflito em atender às exigências da CAPES ou seguir os seus propósitos como pesquisador, pois muitas vezes podem se tornar contraditórios e intrigantes do ponto de vista pessoal:

Hoje não interessa muito a essência do teu trabalho. Interessa, mas ele não é tão relevante. Você pode fazer um $A_{1}$, um $A_{2}$ e para cumprir a regra você faz 50 D2. Então, você não tem um estímulo, tempo para fazer teses e artigos relevantes. As pressões da academia geram certa angústia. Você tem que jogar a regra do jogo, ao mesmo tempo fazer boas escoIhas, então a gente resiste um pouco em jogar o jogo (E 17).

Resiste, mas joga, poderíamos dizer. Conforme Bourdieu (1983, p. 63), "é como se, embora em postos separados, estivéssemos no mesmo campo, sendo coniventes e, embora adversários, cúmplices".

Diante do "Modelo CAPES de Avaliação", e o que ela representa no contexto atual, como disse Sguissardi (2009, p. 170):

[...] a nota baixa do curso não é um bom negócio também para os docentes/pesquisadores, isto é, para os Programas e para a Instituição de Ensino Superior (IES) que os abrigam. E porque não é um bom negócio - quando a meta, o horizonte, deve ser o ‘bom negócio' garantido pela nota alta - é que esses procedimentos e ações de regulação e controle, isto é, o "Modelo CAPES de Avaliação", possuem um alto poder indutor de homogeneidade, se não de uniformidade e conformismo [...]. 


\section{Estratégias UTILIZADAS PARA ATENDER Às EXIGÊNCIAS dA CAPES}

Nossos entrevistados falaram sobre as estratégias que utilizam para responder às exigências da avaliação da CAPES, em termos de produção/publicação, conforme podemos observar no quadro a seguir.

Quadro 2. Estratégias utilizadas para atender as exigências da CAPES.

\begin{tabular}{|l|c|}
\hline \multicolumn{1}{|c|}{ Estratégia } & Número \\
\hline Trabalhar final de semana/à noite/de madrugada & 16 \\
\hline Colaboração/parceria com orientandos/orientados/bolsistas & 11 \\
\hline Colaboração/parceria com professores & 07 \\
\hline Aproveitar os dados/diagnósticos/contatos do campo profissional & 06 \\
\hline Ter organização/planejamento/disciplina & 06 \\
\hline Reduzir tempo de atuação na profissão liberal & 04 \\
\hline Aproveitar o tempo livre na profissão liberal & 04 \\
\hline Reduzir o espaço de atuação e clientes na profissão liberal & 01 \\
\hline Compartilhar com a esposa trabalhos e orientandos & 01 \\
\hline Diminuir o número de orientandos & 01 \\
\hline Reduzir o contrato de trabalho de 40 para 20 horas semanais & 01 \\
\hline Alimentar-se bem e fazer atividade física & 01 \\
\hline Trabalhar nas férias & 01 \\
\hline
\end{tabular}

Fonte: Elaborado pelos autores, a partir de dados da pesquisa.

Nota-se que a grande maioria dos entrevistados, ou seja, 16 deles, afirmaram utilizar como estratégia para dar conta da produção trabalhar final de semana/à noite/de madrugada. O tempo de descanso, para os professores profissionais liberais que têm dupla jornada de trabalho, em tempos de produção e competição acelerada, é sacrificado para atender aos dispositivos de avaliação em vigor. Às vezes você não descansa à noite, porque precisa ficar as noites inteiras fazendo experimento $e$ vendo os resultados (E04). E complementa outro entrevistado:

Trabalhando no mercado e trabaIhando na academia, a gente acaba tendo que trabalhar, mesmo na própria universidade, muito mais do que os demais professores. No tempo livre tu acabas tendo que escrever e passar final de semana escrevendo. Tem professores que trabalham só na universidade e acham que trabalham demais e a gente trabalha de menos porque trabalhamos em outro lugar, mas acho que eles não têm noção, na verdade, do tempo que a gente passa escrevendo mesmo, produzindo (E02).

Embora pareçam questões pontuais, de interesse individual, esse não é o caso, pois do contrário não teríamos tantos entrevistados nessa mesma condição. Bourdieu (1990, p. 94) alerta, opondo-se à tese de Max Weber, de que são os interesses particulares que minam o legalismo, ou seja, de que "agentes sociais obedecem à regra quando o interesse em obedecê-la supera o interesse em desobedecê-la".

Para o autor, nem as normas nem os interesses, mas o habitus determina a práxis social, pois ele lembra que, além de norma expressa e explícita ou do cálculo racional, existem outros princípios "geradores de práticas".

Isso pode levá-los a fazer concessões, inclusive do seu tempo de lazer, e a entrar num jogo que implica deixar em stand bay sua função crítica. Parece que a opção da "ilusão" é o que faz sentido, pois a busca por produção e luta por veiculação do conhecimento, ou seja, o campo no qual professores e pesquisadores atuam, que constroem e 
que os constrói, permite lembrar a noção de illusio, que é uma espécie de energia social vital que os leva a disputar os interesses simbólicos produzidos pelo campo, conforme bem definiu Bourdieu (1983).

Bianchetti, Valle e Pereira (2015, p. 95) apresentam uma reflexão pertinente sobre esse aspecto:

Presos uns aos outros pela concorrência, inteiramente envolvidos na disputa por classificação e distinção acadêmicas (expressas pelo ranking de credibilidade), os pesquisadores encontram na luta entre parceiros-adversários a razão social de existir, motivo pelo qual são cúmplices ou, no mínimo, coniventes - o mais das vezes involuntários - das coerções que os submetem e os enquadram.

Como segunda estratégia mais citada, por dez deles, aparece a colaboração/parceria com orientandos/orientados/bolsistas. Essa colaboração pode ser em projetos de pesquisa ou na orientação e publicação de dissertações e teses. Nesse aspecto, nossos entrevistados são diretos ao afirmar que: Na verdade, o que a CAPES exige de níveis de publicação, eu penso que a gente só consegue atingir mesmo com a colaboração de orientandos da pós-graduação. (E02). Eles reconhecem que para isso, muitas vezes, os orientandos têm que ficar na parte prática ou mais braçal do processo: Realmente, se não tivesse eles fazendo a parte dura da bancada, a parte experimental, a gente não conseguiria atender (E02). Um dos entrevistados explicita a sua estratégia:

Quando a gente pega o aluno para orientar eu já dou uma enquadrada nele e digo: "Cara, o programa tem metas". Os programas realmente têm nas diretrizes que tem que sair com publicação dos alunos também, então grande parte das publicações saem dessas orientações, as de doutorado e de mestrado (E07).
$\mathrm{Na}$ busca de atender às metas dos PPGs e da CAPES, cabe o alerta de que há banalização em termos de organização de eventos, cuja primeira preocupação são as atrações turísticas sobrepondo-se às atividades acadêmico-científicas. A apresentação de trabalhos em coautorias e organização de coletâneas, às vezes dificulta a aferição do "que é resultado de investigação específica de docente, de discentes ou de efetiva coautoria" (BRASIL, 2004b). Nesse mesmo sentido, Kuenzer e Moraes (2009, p. 187) acreditam que:

[...] o incentivo para que orientadores e orientandos publiquem juntos, a partir de uma crescente participação do corpo discente nos projetos de pesquisa dos orientadores, desvirtua-se, reduzindo-se a um incansável roteiro de sucessivas apresentações em eventos, no exterior e no país.

A estratégia de colaboração/parceria com professores também foi citada por sete entrevistados, demonstrando como o trabaIho coletivo está se tornando uma prática no contexto da PG. Percebe-se pelas suas falas que, mesmo aqueles que apresentavam uma prática mais individualista, estão fazendo esforços para buscar parceiros pesquisadores no desenvolvimento de projetos e no compartilhamento de suas publicações: Eu tenho tentado mudar um pouco essa minha postura individualista, eu busquei outras frentes que foi o trabalho com outros professores que estão entrando no programa (E05). Parcerias, trabalhando com outros colegas, com redes, com alunos orientandos, só assim. Trabalhar individualmente a gente não consegue ter uma produção considerada boa hoje (E11).

Aqui uma inevitável indagação: foi necessário aguardar a indução da CAPES para exercitar o trabalho coletivo?

Uma das questões que apareceram como estratégia para seis entrevistados foi a de aproveitar os dados/diagnósticos/contatos 
do campo profissional. Percebe-se pelas entrevistas o quanto para eles se torna importante ter a experiência e a possibilidade de armazenar dados e ter contato com o meio social da profissão, para ter informações e material empírico para as suas produções. Nota-se que falam com muita propriedade a partir de suas experiências concretas:

De um assunto que me surgiu lá na rotina do mercado, no laboratório de análises clínicas, tem várias publicações e que deram inclusive artigos de impacto interessante. Os meus maiores impactos por enquanto, são assim. Então, é uma conjunção de fatores. Acho que no meu caso aproveitar a rotina do laboratório, lá na prática, lá no mercado, é um grande banco de dados e de informações (E02).

Normalmente, são trabalhos que eu busco a partir desse meu pulso no mercado, daquilo que eu ouço, daquilo que as pessoas falam, por meio da agência de propaganda, daquilo que está lá no mercado, eu acabo buscando temáticas e desenvolvendo trabalhos que geram pesquisas e publicações (E05).

Ter organização/planejamento/disciplina foi citado por seis de nossos entrevistados, o que demonstra o quanto as atividades acadêmicas estão exigindo mudanças nos procedimentos, na escolha do tempo, dos espaços e das funções exercidas na universidade. Para atender às exigências de prazos, número de publicações, orientações, aulas e as exigências do campo profissional, é necessário ter disciplina, organizar-se, como explicitaram alguns deles: [...] então é disciplina, foco e administrar também com a família, em casa, tem uma série de responsabilidades (E13). Outra entrevistada enfatiza:

Eu tenho que ser organizada, eu aprendi isso com o tempo, e mesmo assim nem sempre dá tão certo.
Mas eu estabeleço horários: em tal horário eu sou contadora, esse é o horário de pesquisa e de orientação. O que eu consegui fazer, eu consegui, o que eu não consegui vai ficar para amanhã. Agora é o horário da coordenação, agora é o horário que eu tenho que preparar aula, então eu vou me organizando assim (E09).

Em tempos de "pesquisa administrada", como se referiu Adorno (1995), Bianchetti e Zuin (2012) explicitam que não é de estranhar que as exigências externas passem a ser a base das autoexigências de organização e administração do tempo e dos espaços de produção.

Outra questão que apareceu na fala de quatro entrevistados foi a decisão de reduzir o tempo de atuação na profissão liberal, como estratégia, e aumentar o tempo de dedicação à universidade, a fim de dar conta das exigências da vida acadêmica, como pode ser percebido pelos depoimentos que seguem: $A$ minha estratégia é dividir meu tempo para não pegar muita consultoria, para não pegar uma sobrecarga, então normalmente eu não pego muita empresa, antes eu tinha bastante empresa (E12).

Na verdade, a estratégia que eu adotei para dar conta da CAPES foi ficar o menos tempo possível na clínica. No entanto se eu ficasse mais dias lá, ia ser melhor, ia ter mais prática. Então assim, eu acabo tendo fluxo pequeno lá. No entanto, para mim isso é uma estratégia, porque é dedicar mais tempo para a pós-graduação (E04).

Aproveitar o tempo livre na profissão liberal foi citado por quatro entrevistados. Essa estratégia se refere, principalmente, ao fato de levarem questões e demandas da PG para o ambiente de atuação na profissão liberal. Toda vez que tem uma oportunidade eles aproveitam para ler, corrigir trabalhos e escrever: 
Eu trabalho como plantonista médico da UTI [Unidade de Terapia Intensiva]. Então, eu posso num dia que tá tranquilo, sentar aqui, abrir o computador, desenvolver coisas, escrever. Aproveito e dou aula para os residentes, desenho alguma coisa para que eles desenvolvam em termos de estudo clínico. Eles publicam juntos sempre (E08).

Eu consigo trabalhar, pensar e escrever um paper quando falta um paciente, por exemplo, lá no campo profissional, como dentista. Porque muitos dos meus colegas têm que fazer essa mudança clara, "Agora estou na clínica, agora estou na universidade". Comigo nunca funcionou dessa forma (E11).

Também foram mencionadas, apenas uma vez, as seguintes estratégias: reduzir o espaço de atuação e clientes na profissão liberal, para poder ter mais tempo para dedicar-se à produção: Eu fechei pastas com clientes, eu só atendo agora algumas coisas, no âmbito de $100 \mathrm{~km}$ (E18); compartilhar com a esposa trabalhos e orientandos, uma vez que é da mesma área e podem se ajudar, uma vez que são de IES diferente; diminuir o número de orientandos, pois com muitos orientandos demora mais. Então, com menos alunos, poderia produzir mais, escrever mais (E04); reduzir o contrato de trabalho de 40 para 20 horas semanais na IES, e ocupar esse mesmo tempo com a produção; alimentar-se bem e fazer atividade física, para tentar ter pique para dar conta de tudo isso (E14) e; trabalhar nas férias: "Eu usei para produzir artigo, para poder ficar livre para poder trabalhar no escritório" (E18).

\section{ConsideraÇões FINAIS}

Os profissionais liberais, docentes universitários e pesquisadores em PPGs respeitam e valorizam a avaliação realizada pela CAPES, demonstram conhecer sua importância no sentido de induzir a pesquisa e desenvolver a ciência e a tecnologia do país. Eles afirmam que dão conta das exigências do modelo de avaliação CAPES, que jogam o jogo possível e que usam de estratégias para alcançar o exigido por essa agência reguladora.

De modo geral, apontam de forma clara e objetiva três problemas a serem superados no atual modelo de avaliação, quais sejam: a CAPES muda a regra do jogo olhando para o retrovisor, ou seja, apresenta as regras para o quadriênio concluído e não antes do seu início; a CAPES induz à quantidade/o número de publicações - consideram que o "campo CAPES" dá mais valor ao número das publicações do que a qualidade do "produto"; a CAPES pouco ou nada analisa em termos da relevância da pesquisa, pois percebem que a relevância social dos produtos da pesquisa é pouco ou nada valorizado no modelo de avaliação.

A partir deste estudo, chega-se à conclusão de que há "necessidade de avaliar a avaliação, buscando novos formatos que avancem para além dos resultados conseguidos e superem os limites do modelo em curso", como já observaram Kuenzer e Moraes (2009, p. 191).

Os profissionais liberais, que são também pesquisadores dos PPGs, utilizam diferentes estratégias para se manterem produtivos e atenderem às exigências da CAPES, de publicações qualificadas. Nesse sentido, $\mathrm{O}$ estudo demonstrou o seguinte conjunto de estratégias: trabalhar nos finais de semana, à noite e na madrugada; trabalhar em colaboração e parceria com orientandos, ex-orientandos e bolsistas de iniciação científica; trabalhar em parceria com professores do PPG ou em colaboração e redes com professores de outros PPGs e IES; aproveitar ao máximo os dados, os diagnósticos e os contatos do campo profissional em que atuam; ter organização, planejamento e disciplina, para atender às diversas demandas; reduzir tempo de atuação na profissão liberal, para ter mais tempo à pesquisa e publicação; aproveitar os espaços e tempos livre na profissão liberal, na falta de clientes, para leitura e escrita de 
artigos; reduzir o âmbito de atuação e clientes na profissão liberal para ter mais tempo para a pesquisa e produção de artigos; compartilhar com a esposa, também, professora pesquisadora, trabalhos e orientandos para potencializar a produção acadêmica; diminuir o número de orientandos para ter mais tempo para disponibilizar a pesquisa e a publicação; reduzir a carga horária de atuação na IES para ter mais tempo e tranquilidade para escrever e publicar; alimentar-se bem e fazer atividades físicas para ter saúde e disposição para pesquisar, escrever e publicar mais; trabalhar nas férias na produção de artigos para poder continuar na profissão liberal.

Nossos entrevistados, conscientemente ou não, estão permanentemente participando de lutas concorrenciais no campo científico no âmbito da PG, com a finalidade de atenderem às exigências do modelo de avaliação da CAPES, isso em termos de produção/publicação, mas, também, em relação aos seus pares no trabalho como profissionais liberais. Como acredita Bourdieu (1983), os agentes portadores de um quantum de capitais, sejam eles culturais, sociais, científicos, políticos, econômicos ou de outra natureza, estão continuamente contestando e ou aceitando diretrizes que redefinem as bases da sociedade. E essas interferências, essas lutas concorrenciais, ocorrem também na universidade enquanto instituição social que congrega agentes que atuam em campos de natureza diferente, mesmo sendo todos professores, pesquisadores.

\section{REFERÊNCIAS}

ADORNO, T. Palavras e sinais: modelos críticos, 2. ed. Petrópolis: Vozes, 1995, 262 p.

BAZZO, V. L. Constituição da profissionalidade docente na Educação Superior: desafios e possibilidades, 265s. Tese (Doutorado em Educação). Faculdade de Educação. Universidade Federal do Rio Grande do Sul, UFRGS. Porto Alegre, 2007.

BIANCHETTI, L. Os dilemas do Coordenador de Programa de Pós-graduação: entre o burocrático-administrativo e o acadêmico-pedagógico. In: . SGUISSARDI, V. (Orgs.). Dilemas da pós-graduação. Gestão e avaliação. Campinas, SP: Autores Associados, p. 15-99, 2009.

BIANCHETTI, L.; ZUIN, A. A. S. O intelectual universitário e seu trabalho em tempos de "pesquisa administrada". Educ. rev. [on-line]. Minas Gerais, v. 28, n. 3, p. 55-75, 2012.

BIANCHETTI, L.; VALLE, I. R.; PEREIRA, G. R. de M. O fim dos intelectuais acadêmicos?: induções da CAPES e desafios às associações científicas. Campinas: Autores Associados, 2015, 144 p.

BOURDIEU, P. O campo científico. In: ORTIZ, R. (Org.). Pierre Bourdieu: sociologia. São Paulo: Ática, 1983.

. Coisas Ditas. São Paulo: Brasiliense, 1990, 229 p.

. La Domination. Conference à l'Université de Rouen, le 26 de novembre 1997.

. O poder simbólico, 2. ed. Rio de Janeiro: Bertrand Brasil, 1998.

. Contrafogos 2: por um movimento social europeu. Rio de Janeiro: Zahar, 2001, 115 p.

. Esquisse pour une auto analyses. Paris, Raisons d'Agir, 2004.

. A distinção: crítica social do julgamento, 2. ed. Porto Alegre, RS: Zouk, 2013, 560 p.

. Homo Academicus, 2. ed. Tradução Ione Ribeiro Valle e Nilton Valle. Florianópolis: Edutora da UFSC, 2017, $310 \mathrm{p}$. 
BRASIL. Lei de Diretrizes e Bases da Educação: Lei nº 9.394/96 - 24 de dez. 1996.

. Decreto $\mathrm{n}^{\circ}$. 86.791, de 28 de dezembro de 1981.

. MEC.CAPES. Portaria n. 068, de 3 de agosto. Brasília, CAPES, $2004 \mathrm{~b}$.

2018. . MEC.CAPES. http://www.capes.gov.br/historia-e-missão - acesso em 23 de janeiro de

CUNHA, M. I. da; LEITE, D. Decisões pedagógicas e estruturas de poder na universidade. Campinas: Papirus, 1996.

HORTA, J. S. B. Avaliação da pós graduação: com a palavra os coordenadores de Programas. In: BIANCHETTI, L.; SGUISSARDI, V. (Orgs.). Dilemas da Pós-Graduação: gestão e avaliação. Campinas, SP: Autores Associados, p. 101-131, 2009.

KUENZER, A.; MORAES, M. C. M. Temas e tramas na pós-graduação em educação. Educação e Sociedade. Campinas, v. 26, n. 93, p. 1.341-1.363, set./dez. 2005.

. Temas e tramas na pós-graduação em educação. In: BIANCHETTI, L.; SGUISSARDI, V. (Orgs.). Dilemas da pós-graduação. Gestão e avaliação. Campinas, SP: Autores Associados, p. 177-206, 2009.

MENDONÇA, A. W. P. C. A pós-graduação como estratégia de reconstrução da universidade brasileira. Educar em Revista. Curitiba: Setor de educação da UFPR, n. 21, p. 289-308, 2003.

ORTIZ, R. (Org.). Sociologia. São Paulo: Ática, 1983.

SAVIANI, D. “A pós graduação em educação no Brasil: pensando o problema da orientação”. In: BIANCHETTI, L.; MACHADO, A. M. N. (Orgs.). A bússola do escrever: desafios e estratégias na orientação e escrita de teses e dissertações, 2. ed. São Paulo: Cortez/Florianópolis, Editora da UFSC, p. 135-163, 2006.

SGUISSARDI, V. A avaliação defensiva no "Modelo CAPES de Avaliação": é possível conciliar avaliação educativa com processos de regulação e controle do Estado? In: BIANCHETTI, L.; SGUISSARDI, V. (Orgs.). Dilemas da pós-graduação. Gestão e avaliação. Campinas, SP: Autores Associados, p. 133-206, 2009.

VALLE, I. R. A obra do sociólogo Pierre Bourdieu: Uma irradiação Incontestável. Educação e Pesquisa, São Paulo: FEUSP, v. 33, n. 1, jan./abr., p. 117-134, 2007.

VOLPATO, G. Profissionais liberais professores: Aspectos da docência que se tornam referências na educação superior, 1. ed. Curitiba: editora CRV, 2010, 201 p.

\section{SOBRE OS AUTORES}

\section{GiLDO VOLPATO}

Doutor em Educação pela Universidade do Vale do Rio dos Sinos - UNISINOS/RS. Professor do Programa de Pós-Graduação em Educação da UNESC/SC. Pós-doutorando em Educação na UFSC.

E-mail: giv@unesc.net. 


\section{IONE RIBEIRO VALLE}

Doutora em Ciências da Educação pela Faculdade de Ciências Sociais - Sorbonne, Universidade René Descartes - Paris V. Estágio Pós-doutoral pela École des Hautes Études en Sciences Sociales - Paris. Professora do Programa de Pós-graduação em Educação da UFSC. Bolsista de Produtividade em Pesquisa do CNPq - Nível 1D.

E-mail: ione.valle@ufsc.br.

\section{LUCÍDIO BIANCHETTI}

Doutor em Educação: História, Política e Sociedade, pela PUC/SP. Estágio Pós-doutoral na Universidade do Porto, PT. Professor Aposentado Voluntário no Programa de Pós-graduação em Educação da UFSC. Bolsista de Produtividade em Pesquisa do CNPq - Nível 1B.

E-mail: lucidiob@gmail.com.

Recebido em: 4 de abril de 2018

Aprovado em: 15 de junho de 2018 